Energy Policy Institute's Seventh Annual Energy Policy Research Conference

\title{
Design choices and equity implications of community shared solar ${ }^{\text {is }}$
}

\author{
Gabriel Chan ${ }^{\mathrm{a}, *}$, Isaac Evans ${ }^{\mathrm{a}}$, Matthew Grimley ${ }^{\mathrm{a}}$, Ben Ihde ${ }^{\mathrm{a}}$, Poulomi Mazumder ${ }^{\mathrm{b}}$ \\ ${ }^{a}$ Humphrey School of Public Affairs, University of Minnesota, United States \\ ${ }^{\mathrm{b}}$ Department of Electrical and Computer Engineering, University of Minnesota, United States
}

\section{A R T I C L E I N F O}

\section{Keywords:}

Shared solar

Community solar

Solar

Renewable energy

Energy policy

Utility business model

Net energy metering

\begin{abstract}
A B S T R A C T
What is the best way to deploy solar energy to maximize clean energy growth while equitably sharing benefits? A promising model is community shared solar, which enables energy consumers to purchase shares of electricity generated in an offsite project. Noting how different states and utilities have approached program design, we explore how design decisions affect access to solar and the equity of cost and benefit sharing. We conclude with a set of questions for future research.
\end{abstract}

\section{Introduction}

The challenges associated with broadening access to technology and equitably distributing costs and benefits in the transition to sustainability is a growing area of scholarship (Anadon et al., 2016). Within this context, the rapid deployment of solar energy is seen as a key strategy to mitigate climate change and reduce other environmental impacts of energy use (IEA, 2016). In the United States, solar energy adoption is growing rapidly, but as of 2015, solar comprised less than $1 \%$ of national electricity generation (EIA, 2017). While the hardware costs of solar have dropped considerably in the past decades, large-scale solar deployment presents a significant financing challenge, as the majority of lifetime costs associated with solar deployment are upfront costs incurred at the time of construction. As a result, innovation in "finance and business solutions to expand access to capital" is a major focus of public policies to address the non-hardware costs ${ }^{1}$ of installing solar power (U.S. Department of Energy, n.d.).

One promising approach to addressing solar energy's financing challenges is community shared solar (CSS) programs. ${ }^{2}$ CSS programs are now mandated by legislative policies in at least 15 states (and the District of Columbia) and have been voluntarily adopted by an increasing number of electric utilities. Traditionally, solar deployment has required either centralized planning for large, utility-scale project development or for energy customers to own or finance single solar projects located on their own property. In contrast to traditional models, CSS programs allow multiple electricity consumers, often in close geographic proximity, to collectively finance an offsite, centralized solar project by purchasing shares or subscriptions to power generated by the project. Participants who finance the development of a CSS project receive compensation for electricity generated by their

\footnotetext{
is The authors thank seminar participants at the University of Minnesota, Florida State University, and the Energy Policy Research Conference for comments and suggestions. This work

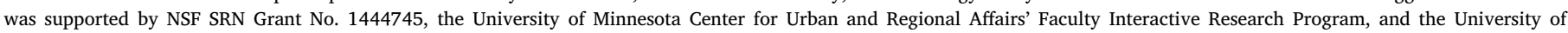

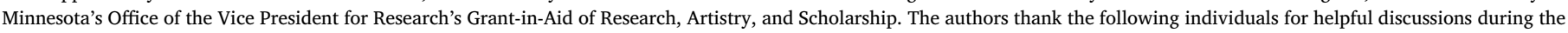

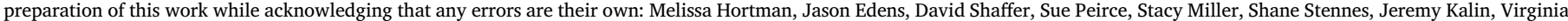

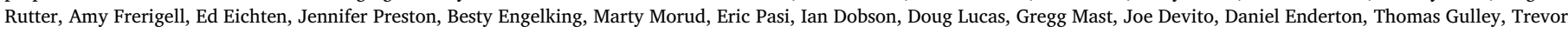

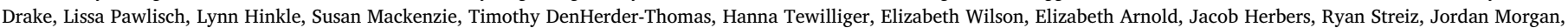
Nick Neuman, and Maureen Hoffman.

* Corresponding author at: 612-626-3292 Humphrey School of Public Affairs, University of Minnesota, 301 19th Ave S, Minneapolis, MN 55455, United States.

E-mail address: gabechan@umn.edu (G. Chan).

${ }^{1}$ The U.S. Department of Energy estimates that the non-hardware costs, or "soft" costs, comprise 64\% of the total installation cost of a new solar power system (U.S. Department of Energy, n.d.).

${ }^{2}$ CSS programs are distinct from, but share several similarities with, green pricing programs. Green pricing programs allow electricity consumers to pay a premium on their electricity

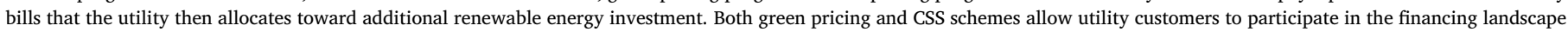

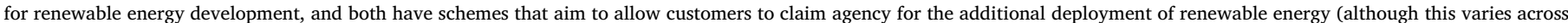

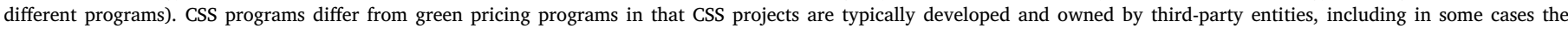

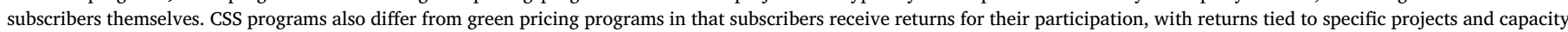

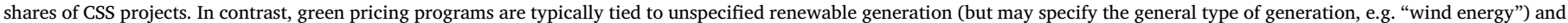
do not yield returns to participants.
} 
share in the project, typically through so-called "virtual net metering" (VNM) schemes. VNM allows subscribers to receive economic returns for electricity sold to a utility generated from the share of the solar project to which they are subscribed.

CSS programs are generally supported for their potential to increase the rate of solar deployment and expand opportunities to finance solar energy more affordably (Chwastyk and Sterling, 2015; National Renewable Energy Laboratory, 2014). First, relative to rooftop installations, CSS projects can lower average costs of solar energy by capturing economies of scale and by targeting more desirable project sites (National Renewable Energy Laboratory, 2014). Second, CSS programs may be made inclusive to customers who may not otherwise be able to access solar, creating an opportunity to address existing inequities in the energy system. Third, because they pool together many consumers, CSS programs are amenable to affordable finance models, thereby creating the potential to address existing inequities in the energy system for customers currently prevented from having their own solar systems (Funkhouser et al., 2015; National Renewable Energy Laboratory, 2014; Stanton and Kline, 2016). Finally, CSS programs may provide unique opportunities for community-level mobilization of resources (Schroederet al., 2016), which could enable niche-level technology adoption as part of a larger-scale energy transition (Geels and Schot, 2010).

In this paper, we explore the diversity of CSS program design options and discuss the key tensions in existing programs. We highlight three critical design choices: the ownership model for CSS projects, rate design to compensate CSS project developers, and subscriber enrollment. Then, we turn to a discussion of how CSS programs may have equity implications that differ from alternative models of deploying solar energy. Finally, we conclude by sketching out key unanswered questions that we believe should be addressed by future research.

\section{Design considerations in community shared solar}

CSS programs aim to achieve two related objectives: (a) increase the overall level of solar energy deployment, and (b) broaden access to the benefits of adopting solar energy (Chwastyk and Sterling, 2015; Funkhouser et al., 2015). By expanding the market for solar energy adoption to electricity customers who cannot self-finance solar projects, CSS programs potentially double the number of residential and commercial electricity customers who can access solar energy (Feldman et al., 2015; National Renewable Energy Laboratory, 2014). And by creating new opportunities for consumer-financed solar deployment, CSS programs potentially lower the balance of costs for deploying new solar energy.

As states and utilities consider adopting or reforming CSS programs, it is critical to build on the experience of the electric utilities and states that have been early adopters. No two CSS programs are identical (Augustine and McGavisk, 2016; Coalition for Community Solar Access, 2016; Interstate Renewable Energy Council, 2016), and this heterogeneity in program design enables a useful context to learn about the impact of various CSS program design features.

\subsection{CSS program design choices}

Taxonomies of CSS program design choices have been proposed by several different groups. Chwastyk and Sterling (2015), writing for the non-profit Solar Electric Power Association, identify "12 key decisions" that define a CSS program. A recent study by researchers at Princeton University identifies nine characteristics that define a CSS program (Chang et al., 2017). Writing in this journal, Augustine and McGavisk (2016) propose a taxonomy of five program design considerations. We briefly summarize Augustine and McGavisk's five considerations here, supplementing their taxonomy with elements from the broader literature:
1) Ownership model: projects within a CSS program may be owned by a utility, a third party, a special-purpose entity created by a utility or by customers, or a charitable nonprofit. Ownership models have direct implications on how a project is financed.

2) Subscription model: CSS programs may allow customer participation through offers to buy or lease solar panels, invest a fixed amount in the system, or buy energy or capacity. Within these different models, customer payments may be upfront, paid over the course of the contract, or credited on monthly electric bills.

3) System and site selection: CSS programs may allow developers to site projects in specific locations or more generally, and may have specific rules regarding grid interconnection, power purchasing, net metering, and other aspects of rate design and developer compensation.

4) Subscriber enrollment: CSS programs vary in how they recruit subscribers. Some engage in extensive community engagement, outreach, and marketing campaigns, while others will use existing channels between a utility and their customers. Subscriber enrollment may have certain restrictions or additional incentives for certain customer types, such as low- to moderate-income (LMI) customers.

5) Program management: Over the lifetime of a CSS project, operations and maintenance must be performed and bill and subscription management must be carried out (e.g. managing unsubscribed electricity and subscriber attrition). Programs vary in their implementation of these functions and which actors bear responsibility for these functions. Program management may also include consumer protection, data reporting, and regulatory compliance.

In the taxonomy of CSS program design choices presented above, several key features have emerged as being particularly important in overall program performance. Here we highlight three issues for deeper exposition: ownership model, rate design, and subscriber enrollment (note: rate design is an element of "system and site selection" in Augustine and McGavisk's taxonomy). We note however, that even if every aspect of program design is considered in the creation or evaluation of a CSS program, one must recognize that each of the decisions, "is made within the context of the greater regulatory and utility regime, and can affect one another" (Chwastyk and Sterling, 2015).

\subsubsection{Ownership model}

Program designers must take into account the utility structure in every context where CSS operates. CSS is inherently flexible and therefore offers different benefits to the utility and customer (Funkhouser et al., 2015; Trabish, 2017). The most common differentiation in the literature is between utility-owned and third-party-led programs (Coughlin et al., 2011), although special-purpose entity (SPE) ownership models and non-profit models have also been implemented. Here we present tradeoffs between these different ownership models, extending the comparison by Augustine and McGavisk (2016).

In utility-administered programs the utility is in charge of every aspect of CSS construction, interconnection, design (subject to constraints by the legislature), operation, and billing. These programs are more likely to occur in vertically integrated, regulated utilities than in deregulated states (Stanton and Kline, 2016). Smaller municipal utilities, and electric cooperatives have generally begun their foray into CSS through programs of less than $500 \mathrm{~kW}$ and contract out specific support services (billing, operations, maintenance) (Chwastyk and Sterling, 2015). In several states, electric cooperatives were the early adopters of CSS, and offered a combination of up-front and pay-as-yougo payment options. This earlier experience in some states appears to have influenced the wider adoption of CSS programs, including through legislation. Larger investor-owned utilities (IOUs) may begin with a pilot program but generally have larger programs of over $20 \mathrm{MW}$ (Chwastyk and Sterling, 2015). Finally, utility-led programs tend to use virtual net metering where the participant receives a credit for their 
portion of the solar project (Coughlin et al., 2011).

The benefits to utilities in utility-led programs may be significant. The utility maintains control over the distributed generation project, demand continues to pass through the utility, renewable energy credits can be retained and retired against the utility's RPS where applicable, and the utility can improve relations with its ratepayers (Funkhouser et al., 2015; National Renewable Energy Laboratory, 2014). The utility would also qualify for rebates, incentives, and the modified accelerated cost recovery system (MACRS) and may also be able to more readily take advantage of federal and state tax credits, all of which can reduce the costs of developing the CSS project. These benefits could in theory be indirectly passed on to subscribers, but whether or not benefits flow to subscribers depends on program design (Coughlin et al., 2011).

In third-party or non-utility-SPE programs, CSS project developers partner with utilities to develop, manage, and maintain the solar array, assign subscribed generation or capacity to utility accounts, or sell their electricity to the utility through a power purchasing agreement (PPA) (Chwastyk and Sterling, 2015; Coughlin et al., 2011). The utility is charged with facilitating the billing, interconnection, and management of the distribution system (Trabish, 2017). These programs have proliferated in regulated states with larger IOUs and through legislated shared solar policies, as in Colorado and Minnesota. Non-profit thirdparty CSS developments have also emerged where the project is wholly owned by the subscribers. Though few in number, they have been successful in developing CSS models that more actively include LMI subscribers (Chwastyk and Sterling, 2015; Louwagie, 2017). These ownership models may encounter difficulties with capturing the full tax benefits, as non-profits and customer SPEs may not have access to a taxequity partner.

As opposed to utility-led programs, third-party programs diminish the value to the utility that administers the program. The utility either signs a PPA with a special purpose entity or works with a developer by administering the program (Chwastyk and Sterling, 2015; Coughlin et al., 2011). In both cases, the utility does not own the solar array. This is an important consideration when creating a program, given the extent to which the utility could resist such infringements into its territory by third party developers - either directly or indirectly (such as delaying the interconnection process in the case of vertically integrated utility territories). The relative opaqueness, cost, and length of the siting and interconnection process can increase the uncertainty for developers and financiers, and slow the speed of program rollout. States that have caps on net metering project sizes in addition to limits on how much energy production can be credited "increase the risk and may slow or halt solar project development," if developers are uncertain about whether or not their development will qualify (National Renewable Energy Laboratory, 2014). Additional legislation may be required to facilitate such development (Stanton and Kline, 2016). Finally, third-party-led programs may still qualify for rebates, incentives, and MACRS that can be retained by the developer or once again passed onto participants indirectly (Coughlin et al., 2011).

\subsubsection{Rate design}

Rate design and the customer subscription offer are arguably the most essential aspects of designing a CSS program that meaningfully increases the deployment of solar. The most common ways of crediting CSS developers are tariffs based on virtual net metering (Chang et al., 2017; Funkhouser et al., 2015; National Renewable Energy Laboratory, 2014). A stable, transparent, and appropriate tariff lowers the financial risk that financiers see with CSS by increasing the predictability of returns (Chang et al., 2017).

Like net metering schemes for other forms of distributed energy generation, tariffs paid to CSS subscribers through VNM schemes vary and may be above, equal to, or below retail electricity rates. CSS programs face unique challenges in tariff design, as projects can have significantly greater capacity than other third-party-owned and operated solar facilities on the grid. As such, there has been experimentation in tariff design in the context of VNM for CSS programs. For example, the legislatively mandated CSS program for the state's largest investorowned utility in Minnesota has been one of the first tariff programs (for any form of power generation) to adopt a value-of-solar compensation scheme (Miller, 2016; Taylor et al., 2015). ${ }^{3}$

\subsubsection{Subscriber enrollment}

Subscriber enrollment with CSS programs has proved to be a challenge in some, but not all, CSS programs. Where subscriber acquisition has been a barrier to CSS deployment, utilities and developers have often underestimated the time and cost of marketing the program (Augustine and McGavisk, 2016). Barriers to subscriber enrollment can stem from the unfamiliarity of CSS programs for customers and the entrance of third-party entities into the middle of utility-customer relationships.

In terms of customer acquisition, experience with CSS programs has pointed to a tradeoff between the number of subscribers needed to fully subscribe a CSS project and the risk of under-subscription (Chwastyk and Sterling, 2015). In order to counter some of this risk, many programs and developers, especially in immature markets, have opted for contract lengths between 20 and 25 years, despite customer preferences being between 5 and 10 years (Chwastyk and Sterling, 2015; Stanton and Kline, 2016; Trabish, 2017). Customers may balk at such long commitments if appropriate transfer options are not in place. But customer screening may also be occurring in other ways.

In many CSS programs, customers must pass a credit check and be deemed creditworthy before being allowed to subscribe to a project. In some circumstances this can be an important way to reduce a project owner's financial risk. However, because of the correlation between credit scores and income, credit screens may also make CSS programs more inequitable by excluding LMI households. This can be particularly problematic in CSS programs where customer subscriptions are not providing a primary source of finance (in these schemes, favorable tariffs, tax credits, and other incentives are playing the key financing role). Particularly in CSS programs with tariffs that are set above or near retail electricity rates, subscribers may be playing a minimal role in raising project finance for CSS projects. In this case, the revenue to support the CSS tariff is typically borne by ratepayers and taxpayers (including LMI households), but if LMI households are excluded from benefitting from the passed-through benefits of solar incentives, inequity in CSS schemes may be exacerbated.

The cost for subscribers to participate in CSS program can dramatically affect participation levels. Many of the financial benefits to consumers outlined above, and the incentives for developers in thirdparty-led utility programs stem from having a rate that credits subscribers favorably for their share of the electricity. In order for CSS programs to be financially attractive propositions, the rate the subscriber pays must be lower than the rate that they are credited (Stanton and Kline, 2016). However, subscribers may also be motivated by other considerations, such as positive feelings from supporting green energy or corporate or community goals.

Political power dynamics continue to play a role in CSS offerings, as utilities may seek to use CSS programs to maintain their current utilitycustomer financial relationship and a predictable return for their investors (Funkhouser et al., 2015; Granqvist and Grover, 2016; Rule, 2014). Further erosion of the utility rate-base by customers self-supplying electricity has led to worries over the "utility death spiral," where the utility collects less revenue, drives up rates, inducing more customers to self-supply their energy, thereby exacerbating the cycle.

\footnotetext{
${ }^{3}$ Value-of-solar tariff schemes seek to set compensation for solar generation equal to the full value provided by solar generation to the electric system and general public. The key components of value-of-solar tariffs are avoided costs to the utility (e.g. avoided costs of new capacity), avoided costs to the transmission and distribution system, the costs of connecting solar to the electric grid, and avoided environmental externalities. (Miller, 2016; Taylor et al., 2015).
} 
In some schemes, customer must pay for their subscription up-front or overtime, whether there is a bill credit or line item (on bill) payment, and if there is a refundable down payment to sign up or not (Chwastyk and Sterling, 2015). If the up-front financing costs are too high, or the relationship between monthly payments and expected monthly credits is not balanced correctly, LMI customers may find it particularly difficult to purchase a share of a CSS project (Stanton and Kline, 2016). For these reasons, pay-as-you-go has been viewed by some developers as easier to set up since it is easier to get customers relative to paying upfront (Trabish, 2017).

A final important consideration in subscriber enrollment is the composition of institutional subscribers versus residential subscribers. In some large CSS programs, particularly in IOU utilities, there appears to be a disconnect between the rhetoric of CSS programs, which often focus on attracting residential subscribers in a "community," and the implementation of CSS programs, which have largely attracted large institutional subscribers.

\subsection{Access and equity in CSS}

At the center of the political motivation for CSS program development is a normative goal to increase access to solar energy for those without an adequate roof or finances. The definitions of "access," however, vary across jurisdictions and actor groups. It can mean access to electricity where there wasn't any before, access to ownership of renewable energy credits, access to the opportunity of owning solar, and access to the financial benefits of owning solar.

One important dimension of CSS program impact is the distribution of costs and benefits across actor groups. In standard energy infrastructure investment, costs and benefits are distributed across ratepayers (e.g. through increased electric rates), taxpayers (e.g. government subsidies), and utility shareholders (e.g. through lost profit). The distribution of costs for standard energy investments has been extensively studied in the literature under the heading of "cross-subsidization" (Eid et al., 2014; Faulhaber, 1975; Joskow, 1998). More complex financial and policy contexts complicate the analysis of crosssubsidization, as counterfactual costs and benefits are more difficult to define, as there are many existing policies and rules with complex crosssubsidization effects, on top of which new policies are layered.

Setting aside this analytic complexity, new policy and financial programs add additional conceptual complexity to the analysis of cost and benefit distribution by introducing third parties, new forms of ownership, virtual separation of conceptual components of energy goods (e.g. "green attributes"), and others. In the case of CSS schemes, the distribution of costs and benefits is made complex by the introduction of third-party solar developers, subscriptions - which take heterogeneous forms of compensation schemes - and specific tariff schemes for electricity generated. The distribution of costs and benefits raises the issue of fairness in CSS schemes. Because analysis of these cross-group transfer effects is so complex, CSS programs have been implemented without a broadly agreed upon ex ante understanding of these impacts.

In order to not be regressive, CSS schemes should at least provide LMI customers with access to the financial benefits of building new renewable energy infrastructure in proportion to the costs they bear through taxes and higher rates (Hoffman and High-Pippert, n.d.). In the United States, LMI customers spend the highest share of their household income on energy, with estimates ranging from 5 to $10 \%$ (Drehobl and Ross, 2016; Sabol, 2016). In theory, CSS programs, in centralizing maintenance and finance to an offsite array, perceivably could mitigate risk and costs for LMI customers. Using different financing structures, hybridized contracts, and recruiting different subscriber types, CSS projects could spread financial risk more evenly among its subscribers (Schroeder et al., 2016). In practice, however, CSS programs are in their infancy and given the choice, developers have sometimes pursued wealthier households and large electricity users who pose lower risk of attrition.

Amid growing interest in increasing participation of LMI customers in CSS programs, organizations such as the Interstate Renewable Energy Council (IREC) have released policy recommendations to better include LMI customers in shared renewable energy projects, though there are relatively few concrete examples of programs that target LMI customers (Schroeder et al., 2016). IREC's recommendations suggest greater weight be given to the definitions of who LMI customers are and how programmatic structures target them, what financing mechanisms LMI customers have access to, and what percentage of total CSS project capacity LMI customers should subscribe to.

Debates over the fairness and potential cross-subsidies of solar net metering programs have also spilled into CSS programs. In more general solar net metering debates, low-income customers are said to subsidize higher-income customers who have the money or means to buy solar panels. Yet as one study determined for a hypothetical Southwestern electric utility, federal subsidies for the low-income energy expenditures remain much higher than the potential rate impacts of solar at even $10 \%$ of demand, where net-metered solar was predicted to increase rates by only $2.5 \%$ (Rule, 2014).

\section{Discussion}

CSS programs are relatively new models for solar energy deployment and vary significantly from state to state and utility to utility (Coalition for Community Solar Access, 2016; Interstate Renewable Energy Council, 2016). As such, the performance of CSS programs and the impact of different program design features are not yet well understood. The heterogeneity in program design has created a critical opportunity to reflect on experience thus far to better understand what program design options make CSS programs more effective and equitable. Moving forward, we are in the implementation stage of a broad research agenda on CSS programs to learn from the experience in legislated state programs as well as voluntary utility programs. Our research agenda is motivated by several key questions:

- How do CSS programs shift the distribution of costs and benefits in the deployment of solar energy? To what extent are costs and benefits borne by program participants (CSS subscribers and project developers), utility shareholders, non-participating utility ratepayers, and taxpayers? And particularly within the group of participating and non-participating ratepayers, how equitable are benefit and cost transfers from the implementation of CSS programs?

- Who has agency in CSS programs to deploy additional solar energy? Given the complexity of the real-world policy context in which CSS programs are deployed, to what extent do CSS programs alter political and economic power arrangements and to what extent can participants claim responsibility (or credit) for their effort in deploying solar?

- What explains the heterogeneity in customer participation in CSS programs, particularly programs with low barriers to entry and attractive financial returns? What explains the heterogeneity in CSS program adoption by electric utilities and state policymakers? What are the driving factors for CSS program participation and adoption among these actor groups?

- How do CSS programs compare on different evaluation dimensions (e.g. overall levels of solar deployment, affordability, equity and access, etc.) to other models of solar deployment, such as mandates for utility-scale solar or innovative business models for rooftop solar? What policy and program design options can make CSS programs more effective and equitable?

We look forward to engaging with the broader research and practitioner communities on these critical questions as state governments, utilities, and consumers consider if and how to move the community solar agenda forward. 


\section{References}

Anadon, L.D., Chan, G., Harley, A.G., Matus, K., Moon, S., Murthy, S.L., Clark, W.C., 2016. Making technological innovation work for sustainable development. Proc. Natl. Acad. Sci. 113, 9682-9690. http://dx.doi.org/10.1073/pnas.1525004113.

Augustine, P., McGavisk, E., 2016. The next big thing in renewable energy: shared solar. Electr. J. 29, 36-42. http://dx.doi.org/10.1016/j.tej.2016.04.006.

Chang, V., Goldenberg, C., Hoskins, J., Lassiter, S., Li, Z., Nakatani, E., Oluwafemi, S., Safford, H., 2017. Solar Gardens in the Garden State: Community Solar Recommendations for New Jersey.

Chwastyk, D., Sterling, J., 2015. Community Solar: Program Design Models. Solar Electric Power Association.

Coalition for Community Solar Access, 2016. Community Solar Policy Decision Matrix.

Coughlin, J., Grove, J., Irvine, L., Jacobs, J.F., Phillips, S.J., Moynihan, L., Wiedman, J., 2011. Guide to Community Solar: Utility, Private and Non-profit Project Development.

Drehobl, A., Ross, L., 2016. Lifting the High Energy Burden in America's Largest Cities: How Energy Efficiency Can Improve Low Income and Underserved Communities.

EIA,, 2017. Electric Power Monthly.

Eid, C., Reneses Guillén, J., Frías Marín, P., Hakvoort, R., 2014. The economic effect of electricity net-metering with solar PV: Consequences for network cost recovery, cross subsidies and policy objectives. Energy Policy 75, 244-254. http://dx.doi.org/10. 1016/j.enpol.2014.09.011.

Faulhaber, G.R., 1975. Cross-subsidization: pricing in public enterprises. Am. Econ. Rev. 65, 966-977. http://dx.doi.org/10.2307/1806633.

Feldman, D., Brockway, A., Ulrich, E., Margolis, R., 2015. Shared Solar: Current Landscape, Market Potential, and the Impact of Federal Securities Regulation (Technical Report No. NREL/TP-6A20-63892). National Renewable Energy Laboratory.

Funkhouser, E., Blackburn, G., Magee, C., Rai, V., 2015. Business model innovations for deploying distributed generation: the emerging landscape of community solar in the US. Energy Res. Soc. Sci. 90.

Geels, F.W., Schot, J., 2010. The dynamics of transitions: a socio-technical perspective a multi-level perspective on transitions. In: Grin, J., Rotmans, J., Schot, J. (Eds.),

Transitions to Sustainable Development: New Directions in the Study of Long Term Transformative Change. Routledge, New York, pp. 18-28.

Granqvist, H., Grover, D., 2016. Distributive fairness in paying for clean energy infrastructure. Ecol. Econ. 126, 87-97. http://dx.doi.org/10.1016/j.ecolecon.2016.02 012.

Hoffman, S., High-Pippert, A., 2017. Community Solar Programs and the Democratization of the Energy System. University of St.Thomas.

IEA, 2016. World Energy Outlook 2016. OECD Publishing.

Interstate Renewable Energy Council, 2016. State Shared Renewable Energy Program Catalog [WWW Document]. http://www.irecusa.org/regulatory-reform/sharedrenewables/state-shared-renewable-energy-program-catalog/ (Accessed 02.07.17).
Joskow, P.L., 1998. Electricity sectors in transition. Energy J. 19, 25-52.

Louwagie, P., 2017. Leech lake solar garden is first in nation linked to energy assistance program - StarTribune.com. Star Trib.

Miller, A., 2016. A new sunshine state? Evaluating minnesota's value of solar tariff methodology. George Wash. J. Energy Environ. Law 7, 177-188.

National Renewable Energy Laboratory, 2014. Community Shared Solar: Policy and Regulatory Considerations (No. NREL/BR-6A20-62367).

Rule, T.A., 2014. Solar energy utilities, and fairness. San Diego J. Clim. Energy Law 6, 115-148.

Sabol, P., 2016. From Power to Employment: Plugging Low Income Communities Into The Clean Energy Economy.

Schroeder, E., Auck, S., Passera, L., Elder, B., 2016. Shared Renewable Energy for Low-to Moderate-Income Consumers: Policy Guidelines and Model Provisions. Interstate Renewable Energy Council.

Stanton, T., Kline, K., 2016. The Ecology of Community Solar Gardening: A 'Companion Planting' Guide (No. 16-07). National Regulatory Research Institute.

Taylor, M., McLaren, J., Cory, K., Davidovich, T., Sterling, J., Makhyoun, M., 2015. Value of Solar: Program Design and Implementation Considerations (No. NREL/TP-6A2062361). National Renewable Energy Laboratory.

Trabish, H., 2017. Subscriptions or sales: which community solar approach promises the best growth? Util Dive.

U.S. Department of Energy, 2017. SunShot [WWW Document]. URL https://energy.gov/ eere/sunshot (Accessed 02.07.17).

Gabriel Chan is an Assistant Professor at the University of Minnesota's Humphrey School of Public Affairs in the Science, Technology, and Environmental Policy (STEP) area Professor Chan's research examines policies to stimulate innovation in energy technologies and mitigate global climate change in the United States, China, and internationally.

Isaac Evans is a Master's of Public Policy student at the University of Minnesota's Humphrey School of Public Affairs, focusing on environmental policy and sustainable development.

Matt Grimley is a Master's of Science in Science, Technology, and Environmental Policy student at the University of Minnesota's Humphrey School of Public Affairs, focusing on energy policy.

Ben Ihde is a Master's of Science in Science, Technology, and Environmental Policy student at the University of Minnesota's Humphrey School of Public Affairs, focusing on technology and innovation policy.

Poulomi Mazumder is a Master's of Engineering student in the Department of Electrical Engineering at the University of Minnesota, focusing on power systems and control. 